\title{
Mechanical properties and strain rate sensitivity of 3D laser- deposited Ti-6Al-4V alloy
}

\author{
Sanghyun $\mathrm{Woo}^{1,2, *}$, Yerim $\mathrm{Lee}^{2}$, and Leeju Park $^{1,2}$ \\ ${ }^{1}$ Weapon Systems Engineering, Korea University of Science and Technology, 34113 Daejeon, Republic of Korea \\ ${ }^{2}$ The 4th Research and Development Institute, Agency for Defense Development, 34186 Daejeon, Republic of Korea
}

\begin{abstract}
Ti-6Al-4V has become the most common material in titanium alloy. Due to High specific strength, low density and excellent mechanical properties, it has been used in not only living, sports goods but also aerospace, defense industries. Usually these products have complex geometry, so there are a lot of limitations in general manufacturing process. Especially in weapon systems, applied loadings are severe therefore choice of materials is very important. 3D printing method is useful for manufacturing these complicated structure and suitable to discontinued, superannuated part of products. In this study, specimen for experiments is turned out by using $3 \mathrm{~d}$ laser deposition technology which metal powder is injected into the focused beam of a high-powered laser. While lots of studies are mainly concerned with normal process, it is not commonly researched for metallic materials forming through $3 \mathrm{D}$ printing. In the $10^{-3} \sim 10^{3} / \mathrm{s}$ strain rates range, two kinds of plate samples and LDAM Ti-6Al-4V were performed using universal testing machine and SHPB for dynamic material properties. Simplified Johnson-Cook constitutive equation parameters produced from these experiments.
\end{abstract}

\section{Introduction}

Ti-6Al-4V (6wt\% $\% \mathrm{Al}, 4 \mathrm{wt} \% \mathrm{~V}$ hereinafter referred to as Ti64) accounts for more than $60 \%$ of titanium alloy and has widely used typical material in various industries. Demand for this alloy has rapidly increased especially in aerospace, defense and medical industries due to its relatively low density, high specific strength and excellent mechanical properties. It also shows excellent corrosion resistance in oxidization environment and thermal resistance at high temperature.

Those final products in these areas are usually having complicate and complex geometry. These limitations make machining process harder, e.g., high wasting ratio, expensive cost and long working time, etc. Additive manufacturing (AM), commonly referred to as ' $3 \mathrm{D}$ printing' or laser deposition additive manufacturing (hereinafter referred to as LDAM) technology can overcome these restrictions such as reducing supply chain requirements, lower prefabrication production costs and more efficient production lines. Laser engineered net shaping (LENS) and laser solid forming (LSF) technique were proposed by Sandia National Laboratories and Air Force Research Laboratory in 1996, 1997 respectively [1-3].

It is well known that mechanical behaviours under dynamic deformation condition are different to those under quasi-static condition. A few researches have been performed to examine the differences between direct energy deposition (hereinafter referred to as DED) and commercial products at quasi-static states, but those mechanical properties in high strain rates are not clearly figured out until now.

The object of this study is to confirm Ti64 alloy mechanical properties manufactured by using DED comparing with two kinds of commercial products during dynamic deformation. Performing two different strain rate tests $\left(0.001,10^{3} / \mathrm{s}\right)$, mechanical properties of 3 types of Ti64 alloy are examined. The results of the quasi-static and dynamic condition tests are compared.

\section{Experiments}

\subsection{Ti64 alloys manufactured by LPD}

Laser-powder-deposition (hereinafter referred to as LPD) is a manufacturing method of DED which is suitable for process of large size, coating and restoration. The 3D LPD Ti64 used in those experiments is provided by Inc. CetaTech in Korea. Commercial Ti64 powders having diameter less than $150 \mu \mathrm{m}$ were fed into laser with Ar gas by coaxial nozzle system. Powders on the Ti64 substrate were molten by fiber laser with several thousand degrees of temperature. In LDAM laser power process, powder feeding rate and scanning speed are important consideration to get an appropriate process for finished products, it is closely related with product width and height of each layer. Main factors of LPD are listed in Table 1. Succeeding molten pool are deposited on the previous layer, interlayer microstructures are fully compacted and densified by these remelting parts. 
Table 1. Manufacturing variation of LPD process.

\begin{tabular}{|c|c|c|c|c|c|}
\hline $\begin{array}{c}\text { Scan } \\
\text { speed }\end{array}$ & $\begin{array}{c}\text { Feeding } \\
\text { rate }\end{array}$ & $\begin{array}{c}\text { Carrier } \\
\text { gas flow }\end{array}$ & $\begin{array}{c}\text { Spot } \\
\text { size }\end{array}$ & $\begin{array}{c}\text { Laser } \\
\text { Power }\end{array}$ & $\begin{array}{c}\text { Laser } \\
\text { type }\end{array}$ \\
\hline $360 \mathrm{~mm} / \mathrm{min}$ & $10.8 \mathrm{~g} / \mathrm{min}$ & $50 \mathrm{~L} / \mathrm{min}$ & $0.75 \mathrm{~mm}$ & $800 \mathrm{~W}$ & fiber \\
\hline
\end{tabular}

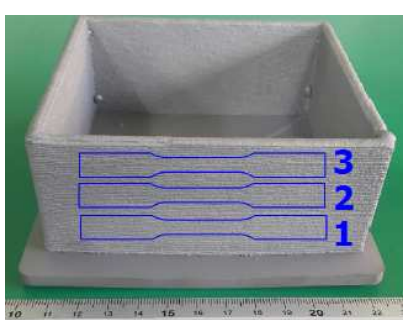

(a) Longitudinal direction

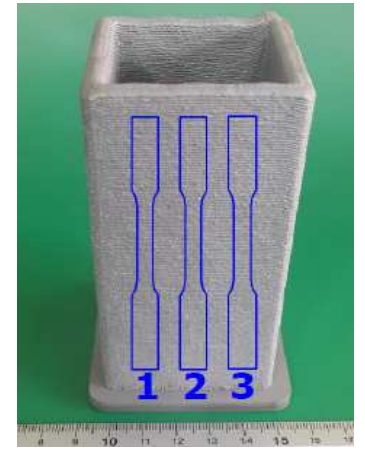

(b) transverse direction
Fig. 1. Ti64 alloys manufactured by LPD.

As shown Fig. 1 manufactured material has two main directions: longitudinal direction denotes the laser scanning direction and transverse direction is along the deposition direction.

\subsection{Mechanical property tests}

Two type of Ti64 alloys were used in this experiment. One is commercial plate product respectively manufactured in USA and China and the other is LPD including two different types which have two and three layered thickness. Material type 2L-L, 2L refers to 2 layered thickness and longitudinal direction. There is no significant difference depending on additive direction condition and layered type in LPD Ti64 alloy, density and chemical composition of alloy is given in Table 2 .

Table 2. Density and chemical composition according to manufacturing conditions in LPD Ti64 alloy.

\begin{tabular}{|c|c|c|c|c|c|}
\hline $\begin{array}{c}\text { Material } \\
\text { type }\end{array}$ & $\begin{array}{c}\text { Density } \\
(\mathrm{g} / \mathrm{cc})\end{array}$ & $\mathrm{C}(\%)$ & $\mathrm{O}(\%)$ & $\mathrm{N}(\%)$ & $\mathrm{H}(\%)$ \\
\hline $\mathrm{L}-2$ & 4.42 & 0.022 & 0.152 & 0.025 & 0.003 \\
\hline $\mathrm{L}-3$ & 4.42 & 0.019 & 0.145 & 0.023 & 0.004 \\
\hline $\mathrm{T}-2$ & 4.42 & 0.02 & 0.16 & 0.031 & 0.003 \\
\hline $\mathrm{T}-3$ & 4.42 & 0.025 & 0.172 & 0.026 & 0.003 \\
\hline
\end{tabular}

Quasi-static tensile tests at low strain rate $(0.001 / \mathrm{s})$ were performed using MTS-810 hydraulic testing machine. Dynamic compression tests at high strain rates $\left(10^{3} / \mathrm{s}\right)$ were performed using split Hopkinson pressure bars (SHPB) also called Kolsky compression bar [4,5]. As shown Fig. 2, general SHPB is consisted of striker, incident and transmission bar.

The striker bar is launched with a gas gun and impact to incident bar generating an incident wave. When it propagates to the specimen, a part of wave is reflected and the rest of wave transmits into transmission bar. The reflected wave signal back into the incident bar and transmit wave signal were recorded with strain gauges on the incident and transmission bars, respectively.

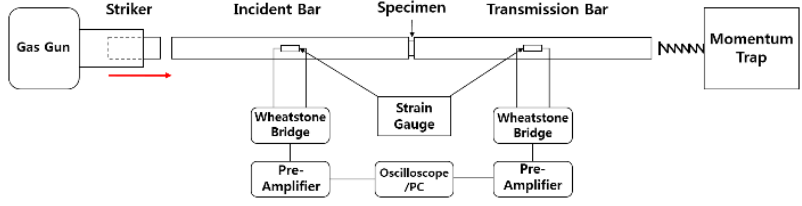

Fig. 2. Split Hopkinson pressure bar apparatus.

$$
\begin{gathered}
\varepsilon=\frac{-2 C_{B}}{2} \int \varepsilon_{R} d t \\
\varepsilon=\frac{-2 c_{B}}{2} \varepsilon_{R} \\
\sigma=\frac{A_{g} E_{B} s_{R}}{A_{z}}
\end{gathered}
$$

SHPB is based on one-dimensional wave propagation, those measured signals can be used to determine the dynamic behaviour of the specimen. During plastic deformation stress equilibrium in a specimen is assumed. In Eqs. ((1) (3)), $C_{B}, E$ and $A_{B}$ are elastic wave velocity, Young's modulus and cross section area of the elastic bars; $\mathrm{L}$ and $\mathrm{A}_{\mathrm{S}}$ are length and cross section area of specimen; $s_{R}$ and $s_{T}$ are the measured reflected and transmitted strain signals.

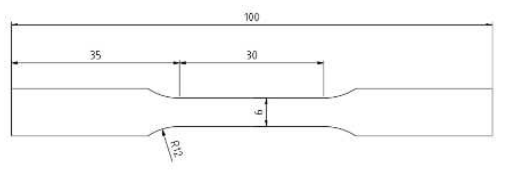

(a) Quasi-static test

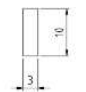

(b) Dynamic test
Fig. 3. Specimen dimension of (a) quasi-static, (b) dynamic test.

C350 maraging steel were used in this study as elastic bars having a diameter of $25.4 \mathrm{~mm}$. The length of striker bar is $250 \mathrm{~mm}$ and incident, transmission bars are same $1500 \mathrm{~mm}$ long. Fig. 3 shows size of specimen at quasi-static and dynamic strain rate, respectively.

\section{Results \& Discussion}

Quasi-static tensile tests were conducted at 0.001/s. As shown Fig. 4, commercial plate products manufactured in USA and china have no big difference. Following the same procedure, LPD Ti64 alloy tensile tests were conducted in longitudinal, transverse directions and heattreated specimens.

General mechanical properties between commercial and LPD Ti64 alloys are similar. It is apparent that longitudinal direction has higher yield strength than transverse direction both 2 and 3 layered sample. As shown Table 3, elongation of L-direction is smaller than T-direction and L-direction properties mostly have a larger deviation than T-direction. It is observed these small differences, LPD Ti64 alloy with no heat-treatment is unstable or has anisotropic mechanical properties with deposition direction. 


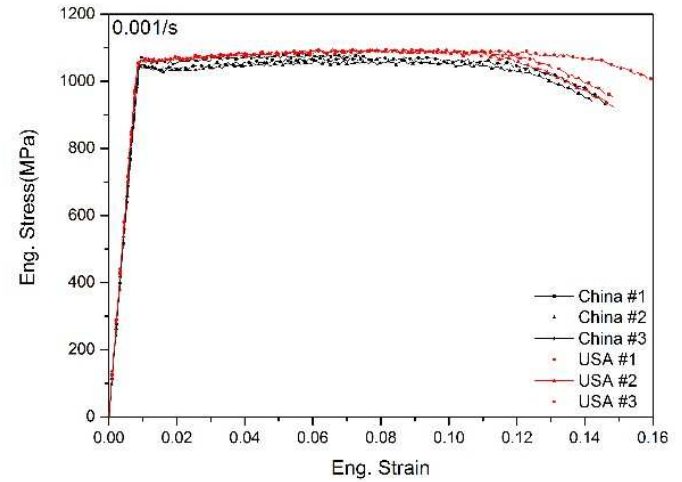

Fig. 4. Commercial products engineering Stress-Strain curve at $0.001 / \mathrm{s}$.

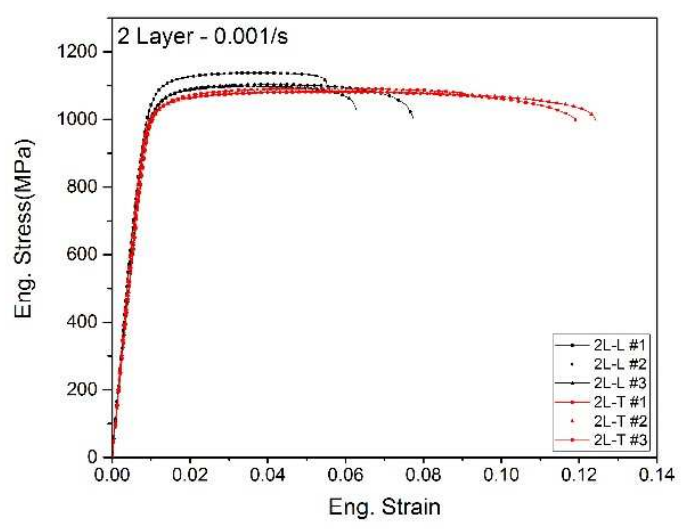

(a) 2 layer

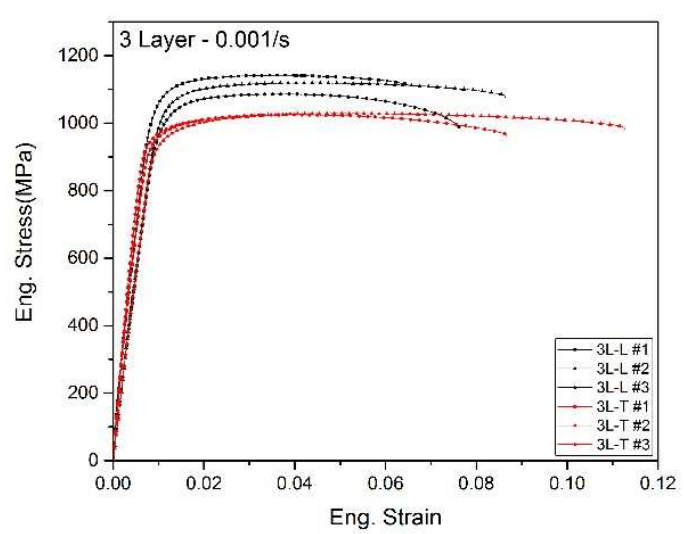

(b) 3 layer

Fig. 5. Engineering Stress-Strain curve LPD Ti64 alloys according to direction and layer type at $0.001 / \mathrm{s}$.

Table 3. Mechanical properties of commercial and LPD Ti64 alloys at quasi-static regime.

\begin{tabular}{|c|c|c|c|}
\hline Material type & Yield St. (MPa) & Tensile St. (MPa) & Elong. (\%) \\
\hline USA & $1043( \pm 11)$ & $1096( \pm 1)$ & $15.3( \pm 0.5)$ \\
\hline China & $1045( \pm 7)$ & $1071( \pm 9)$ & $14.3( \pm 0.3)$ \\
\hline 2L-L & $1036( \pm 19)$ & $1113( \pm 25)$ & $7.3( \pm 1.7)$ \\
\hline 3L-L & $1033( \pm 34)$ & $1116( \pm 30)$ & $8.3( \pm 0.7)$ \\
\hline 2L-T & $1011( \pm 3)$ & $1086( \pm 7)$ & $11.3( \pm 1.3)$ \\
\hline 3L-T & $946( \pm 3)$ & $1027( \pm 2)$ & $11.0( \pm 1.0)$ \\
\hline
\end{tabular}

Heat-treatment in titanium alloy is used to reduce residual stress, produce an optimum combination of ductility, machinability and structural stability. In this study, LPD Ti64 alloy heat-treatment was performed at $1223 \mathrm{~K}$ for 2 hours with argon gas. The experiments using heat-treatment specimens were done following the same process, see Fig. 6 and Table 4.

For comparison purpose, three layered type in longitudinal direction have still large deviation after the heat-treatment. It could be caused by relatively heavy thickness. While the elongation of longitudinal direction became increased after heat-treating, it was decreased in transverse direction. Due to heat-treatment overall strength was lowered than before, but general mechanical properties deviation was decreased.

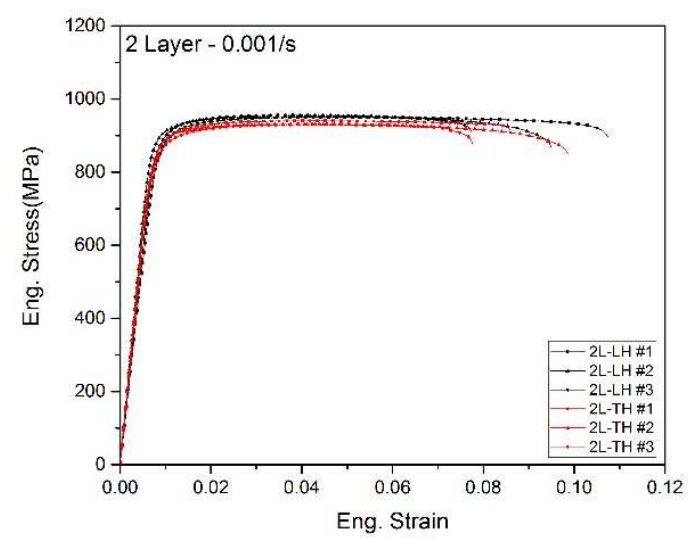

(a) 2 layer

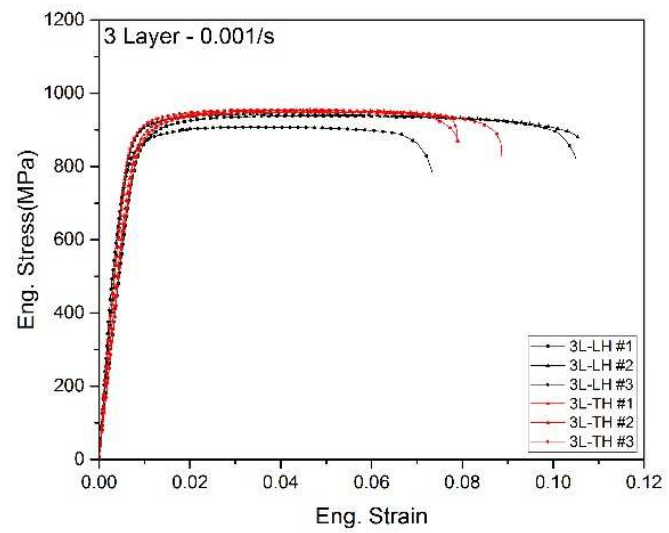

(b) 3 layer

Fig. 6. Engineering Stress-Strain curve LPD Ti64 alloy with heat-treatment at $0.001 / \mathrm{s}$.

Table 4. Mechanical properties of LPD Ti64 alloys with heattreatment at quasi-static regime.

\begin{tabular}{|c|c|c|c|}
\hline Material type & Yield St. (MPa) & Tensile St. (MPa) & Elong. (\%) \\
\hline 2L-LH & $889( \pm 5)$ & $953( \pm 3)$ & $9.7( \pm 1.7)$ \\
\hline 3L-LH & $855( \pm 32)$ & $930( \pm 22)$ & $10.0( \pm 2)$ \\
\hline 2L-TH & $864( \pm 12)$ & $934( \pm 7)$ & $9.7( \pm 1.7)$ \\
\hline 3L-TH & $877( \pm 15)$ & $952( \pm 3)$ & $8.4( \pm 0.5)$ \\
\hline
\end{tabular}

Dynamic compression tests of commercial and LPD Ti64 alloys were conducted using SHPB. Engineering strain, stress and strain rate were calculated with Eqs. (1) - (3). In dynamic tests, engineering strain-stress curves 
of LPD Ti64 alloys in different position, beginning, middle and end, were obtained at similar strain rate by thickness limitations. It was plotted in Fig. 7 with commercial results.

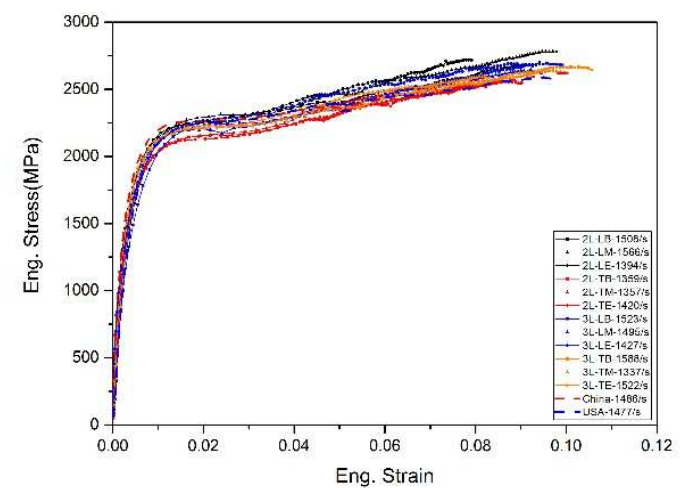

Fig. 7. Engineering strain-stress curve commercial and LPD Ti64 alloys at high strain rates.

As shown Fig. 7, dynamic behaviour of LPD Ti64 alloy had no big differences with commercial products regardless of its position. The yield strength and flow stress were raised with increasing strain rate. Strain dependence seems also similar both of them.

$$
\sigma=\left(A+B \varepsilon^{n}\right)\left(1+C \ln \left(\varepsilon / \varepsilon_{0}\right)\right)\left(1-\left(\frac{T-T_{r q f}}{T_{\mathrm{m}}-T_{r a f}}\right)^{m}\right)
$$

Eq. (4) is simplified Johnson-Cook [6] constitutive model, where $\mathrm{A}, \mathrm{B}, \mathrm{C}$ and $\mathrm{m}$ are yield strength, strain hardening constant, strain rate sensitivity constant and thermal softening constant, respectively. By using quasistatic and dynamic tests results, simplified JC parameters were calculated, as shown in Table 5.

Table 5. Johnson-Cook constitutive model parameters of LPD Ti64 alloy.

\begin{tabular}{|c|c|c|c|c|}
\hline $\mathrm{A}$ & $\mathrm{B}$ & $\mathrm{n}$ & $\mathrm{C}$ & $\mathrm{m}$ \\
\hline 1016.19 & 418.19 & 0.42 & 0.135 & 0.8 \\
\hline
\end{tabular}

\section{Conclusions}

Mechanical property tests of LPD and commercial plate Ti64 alloys were performed at quasi-static and dynamic strain rates using MTS-810 and SHPB.

In quasi-static tensile tests, primary LPD Ti64 without hear-treatment have similar mechanical properties with two commercial products. Longitudinal direction strength is slightly higher and elongation is lower than transverse. For getting isotropic properties heat-treatment was applied to LPD, general qualities were uniform in all directions.

Dynamic behaviour of LPD Ti64 alloys was also analogous with two widely used one in all positions of manufactured samples. Strain rate effects and work hardening tendency seems similar.

Results on different layers of LPD products were confirmed the fact that it has similar properties. For this reason LPD Ti64 alloy has stability at high strain rates compared with commercial one and would be considered as a substitute for complex geometry and replaced Ti64 production process.

The authors would like to acknowledge Ph.D. Kwon at Inc. CetaTech for preparing the LPD Ti64 alloys.

\section{References}

1. M. L. Griffith, D. M. Keicher, C. L. Atwood, et al., Solid Freeform Fabr. Symp. (1996)

2. M. L. Griffith, L. D. Harwell, J. T. Romero, et al., Solid Freeform Fabr. Symp. (1997)

3. M. L. Griffith, M. E. Schlienger, L. D. Harwell, et al., Mater. Des. 20, 107 (1999)

4. B. Hopkinson, Philos. Trans. Royal Soc. London. Ser. A, 437 (1914)

5. H. Kolsky, Proc. Phys. Soc. Sec. B, 676 (1949)

6. G. R. Johnson, W. H. Cook, $7^{\text {th }}$ Int. Symp. on Ballistics, 21, 541 (1983) 